\title{
Optimization of Imidazolium-Based Ionic Liquid-Microwave Assisted Extraction for Oxyresveratrol Extraction from Morus alba Roots
}

\author{
Tanfidz Alishlah', Abdul Mun'im², Mahdi Jufri ${ }^{3, *}$ \\ 'Graduate Programme of Herbal Medicine, Faculty of Pharmacy, Universitas Indonesia, Depok, 16424, West Java, INDONESIA \\ 2Department of Pharmacognosy-Phytochemistry, Faculty of Pharmacy, Universitas Indonesia, Depok, 16424, West Java, INDONESIA \\ 'Laboratory Pharmaceutical Technology and Drug Development, Faculty of Pharmacy, Universitas Indonesia,. Depok, 16424, West Java, INDONESIA
}

\begin{abstract}
Objective: The application of ionic liquids as solvent in the microwave assisted extraction (MAE) method has been developed for extraction of secondary metabolites from plants. However, oxyresveratrol extraction from Morus alba roots using IL-MAE method has never been reported. Purpose of this research was to get the optimum condition of imidazoliumbased ionic liquid-microwave assisted extraction (IL-MAE) for oxyresveratrol extraction from $M$. alba roots. Methods: $M$. alba roots were extracted with 3 kinds of ionic liquids (1-butyl-3-methylimidazolium bromide ([Bmim]Br), 1-hexyl-3-methylimidazolium bromide ([Hmim]Br)and 1-butyl-3-methylimidazolium sulfate $\left([\mathrm{Bmim}]_{2}\left[\mathrm{SO}_{4}\right]\right)$, respectively by microwave with 3 different microwave power (P10\%, P30\% and P50\%) for 10 min. Then, fractionated with ethyl acetate and salted out by additionof 4 different salts $\left(\mathrm{Na}_{2} \mathrm{CO}_{3^{\prime}}\right.$ $\mathrm{NaHCO}_{3}, \mathrm{~K}_{2} \mathrm{HPO}_{4}$, and $\mathrm{NaCl}$ ). Oxyresveratrol concentration of the extracts was analyzed with TLC-densitometry and HPLC. Results: Based on the results of this study, the most optimum condition of IL-MAE for oxyresveratrol from $M$. alba roots was using $[\mathrm{Bmim}] \mathrm{Br}$ concentration $1.5 \mathrm{~mol} / \mathrm{L}$ with microwave power $10 \%$ for $10 \mathrm{~min}$. The salt $0.01 \mathrm{~mol} / \mathrm{L} \mathrm{NaHCO}_{3}$ was optimum for the
\end{abstract}

back extraction of oxyresveratrol from [Bmim]Br solution. Under optimized conditions, oxyresveratrol concentration in $M$. alba roots extract using IL-MAE method was 735.25 ppm. Conclusion: This IL-MAE method was suitable to be applied as an alternative technique to extract oxyresveratrol from the plants.

Key words: Ionic liquid, Microwave-assisted extraction, IL-MAE, Oxyresveratrol, Morus alba, Roots extract.

Key message: Ionic Liquid-Microwave Assisted Extraction seem to be promising method to get optimum oxyresveratrol from Morus alba roots or other plants.

\section{Correspondence}

Dr. Mahdi Jufri, Faculty of Pharmacy, Universitas Indonesia, Depok, 16424, West Java, INDONESIA.

Phone: +62 81310334771

Email: mahdi.jufri@farmasi.ui.ac.id

DOI: 10.5530/jyp.2018.10.61

\section{INTRODUCTION}

The roots of the mulberry plant (Morus alba) are known to have rich in oxyresveratrol and demonstrated a skin lightening effect. Oxyresveratrol is the main content of potential candidates to inhibit dopa oxidase activity from tyrosinase. ${ }^{1}$ Oxyresveratrol is known to have the inhibitory activity of tyrosinase enzyme which is more effective than azelaic acid, curcumin, kojic acid, and mimosa. Oxyresveratrol with a concentration of $0.3-5 \mu \mathrm{M}$ showed inhibition of tyrosinase by $25-84 \%$, in which $50 \%$ inhibition was shown at a concentration of $1 \mu \mathrm{M} .^{2}$ Generally, the root part of the mulberry plant is rarely used commercially. Methanolic extract of $M$. alba roots was reported to have the highest oxyresveratrol content compared to other plant parts of $M$. alba. ${ }^{3}$ Therefore, the study uses mulberry roots.

The method to get the oxyresveratrol from mulberry roots generally used conventional extraction using organic solvents. However, this method has some disadvantages such as low extraction efficiency values, muchneeded solvents, long extraction times, and less environmentally friendly. The microwave-assisted extraction is a fast, efficient and effective extraction method compared to conventional extraction methods such as maceration or reflux. The microwave-assisted extraction method is easier and cheaper if compared with other modern extraction methods. ${ }^{4}$ MAE has been applied to obtains some active compounds from different plants. ${ }^{4}$ Ionic liquid-MAE method on Polygonum cuspidatum roots showed it could obtain the trans-resveratrol content of $92.8 \%$ on first extraction stage, better than methanol-MAE (88\%) or reflux $(84.7 \%){ }^{4}$
The method of extraction using ionic liquid-MAE is a way that has never been done to obtain the more optimum oxyresveratrol content from the mulberry roots. Ionic liquids have the advantages of non-flammable, non-toxic, biodegradable, and non-corrosive characteristic. The ionic liquid extraction method proved to be able to increase the yield of secondary metabolite extraction in plants efficiently. ${ }^{5}$

\section{MATERIALS AND METHODS}

Materials

The roots of M. alba were collected from Rumah Sutera, Bogor, West Java, Indonesia. The roots were washed and dried for six days. The dried roots were ground by using an industrial grinder. The powders were stored in airtight container. Standard oxyresveratrol was purchased from Tokyo Chemical Industry Co., Ltd. (TCI) (Japan). The ionic liquids, 1-Butyl-3-methylimidazolium bromide ([Bmim $] \mathrm{Br}) ; 1$ 1-Hexyl-3-methylimidazolium Bromide ([Hmim]Br); 1-Butyl-3-methylimidazolium sulfate $\left([\mathrm{Bmim}]_{2}\left[\mathrm{SO}_{4}\right]\right)$ were purchased from Chengjie Chemical Co. Ltd., (Shanghai, China). $\mathrm{Na}_{2} \mathrm{CO}_{3}, \mathrm{NaHCO}_{3}, \mathrm{~K}_{2} \mathrm{HPO}_{4}, \mathrm{NaCl}$ were purchased from Merck. All reagents used for HPLC analysis were analytical grade and purchased from a local distributor.

\section{Instrumentation}

Centrifuge (Heraeus Christ GmbH, Osterode, Germany). Vortex (Wise-Mix VM 10, Daihan Scientific Co., Ltd. Korea). Microwave with 
the system supplies $900 \mathrm{~W}$ for $100 \%$ power (Modena MV-3002 with slight modification). TLC equipment - TLC silica gel aluminum plates $60 \mathrm{~F}_{254}$ (Merck, Darmstadt, Germany); Camag microcapillary tube $5 \mu \mathrm{L}$, Camag TLC scanner III (Muttenz, Switzerland), HPLC system (LC-20AT, Shimadzu, Kyoto, Japan).

\section{Preparation of lonic Liquid}

Ionic Liquid (IL) was prepared by diluted each ionic liquid [Bmim] $\mathrm{Br}$, [Hmim] Brand[Bmim $]_{2} \mathrm{SO}_{4}$ with deionized water $100 \mathrm{ml}$ to make concentration $1.5 \mathrm{~mol} / \mathrm{L}, 2.0 \mathrm{~mol} / \mathrm{L}$, and $2.5 \mathrm{~mol} / \mathrm{L}$ respectively.

\section{Determination the optimum IL Solution for IL-MAE}

One gram of $M$. alba roots powder was placed in a boiling flask. $20 \mathrm{~mL}$ of each IL solution with different concentration was added to each flask. The boiling flask was placed into a microwave. The microwave set at power $10 \%$ and run for $10 \mathrm{~min}$. The extract was filtered and diluted in $30 \mathrm{ml}$ of deionized water. ${ }^{4}$ This procedure was repeated three times. For analysis by TLC-densitometry, each $1 \mathrm{ml}$ IL-MAE extracts was diluted with $1 \mathrm{ml}$ ethyl acetate. The solution was vortexed for $20 \mathrm{sec}$, then centrifuged for $15 \mathrm{~min}$ at $3000 \mathrm{rpm}$. Two phases of solution appeared, and the upper layerwas taken for TLC-densitometry analysis.

\section{Thin Layer Chromatography (TLC) - Densitometry Analysis}

Standard ofoxyresveratrol solution was prepared by diluting the oxyresveratrol standard with $80 \%$ ethanol in concentration $1 \mathrm{mg} / \mathrm{mL}$ or $1000 \mathrm{ppm}$. Silica gel $60 \mathrm{~F}_{254}$ was used as a stationary phase and methanol: chloroform: acetate acid $(10: 88: 2 \% \mathrm{v} / \mathrm{v})$ as a mobile phase. Ethyl acetate fractions were spotted $5 \mu$ into TLC plate. The length of chromatogram run was $8 \mathrm{~cm}$ through glass chamber that saturated by the mobile phase. Subsequently, the plate was removed from the chamber and air-dried. The plate was scanned by Camag TLC Scanner III in absorbance wavelength at $366 \mathrm{~nm}$. The TLC-densitometry analysis was operated by winCATS software. Ionic liquid extraction condition with highest area under curve (AUC) spot of oxyresveratrol peak then continued to be analyzed by HPLC.

$$
\text { Oxyresveratrol concentration }=\frac{\text { sample area }}{\text { standard area }} \times \frac{\text { standard volume spotted }}{\text { sample volume spotted }} \times \mathrm{C} \text { standard }
$$

\section{Determination the optimum microwave power for IL-MAE with the chosen IL solution and concentration}

Each one gram of $M$. alba roots powder was placed in a three boiling flask. The chosen IL solution with optimum concentration $20 \mathrm{~mL}$ was added to each flask. The boiling flask was placed into a microwave. The microwave set at power $10 \%, 30 \%$ and $50 \%$ and run for $10 \mathrm{~min}$. The extracts were filtered and diluted with $30 \mathrm{ml}$ of deionized water. This procedure was repeated three times. Then each $1 \mathrm{ml}$ IL-MAE extracts was diluted with $1 \mathrm{ml}$ ethyl acetate. The solution was vortexed for $20 \mathrm{sec}$, then centrifuged for $15 \mathrm{~min}$ at $3000 \mathrm{rpm}$. Two phases of solution appeared, and the upper layer was analyzed by the TLC-densitometry method as mentioned above.

\section{Separation of Oxyresveratrol}

Extract sample with optimum ionic liquid concentration and microwave power from the previous experiment subsequently was separated using salts. The salts used for separation were $\mathrm{Na}_{2} \mathrm{CO}_{3}, \mathrm{NaHCO}_{3} \mathrm{NaCl}$, and $\mathrm{K}_{2} \mathrm{HPO}_{4}$ solution with concentration each $1.0 \mathrm{~mol} / \mathrm{L}, 0.1 \mathrm{~mol} / \mathrm{L}$, and $0.01 \mathrm{~mol} / \mathrm{L}$ respectively. The IL extract and a certain of salt (1:1) were added to a tube. The oxyresveratrol was separated from the ionic liquid solution by back extraction using ethyl acetate in equal amount (1:1). The mixture was vortexed and two clear phases are formed. The top phase was organic phase containing oxyresveratrol, and bottom phase was an aqueous phase. The oxyresveratrol concentration in upper phase was determined by TLC-densitometry as mentioned above.

\section{Determination of Oxyresveratrol by High-Performance Liquid Chromatography (HPLC) Analysis}

Oxyresveratrol content of the extract with optimum ionic liquid and concentration, optimum microwave power and optimum salt was analyzed using HPLC. Standard stock solution $1 \mathrm{mg} / \mathrm{ml}$ of oxyresveratrol in $80 \%$ ethanol. The HPLC analysis was used $\mathrm{C}_{18}$ bonded-silica gel column (YMC, $5 \mu \mathrm{m}, 150 \times 4.6 \mathrm{~mm}$, Phenomenex, Torrance, USA) and system (LC-20AT, Shimadzu, Kyoto, Japan), equipped with a UV-Visdetector (SPD-20A, Shimadzu, Japan) in the isocratic mode. The mobile phase was used acetonitrile: $1 \%$ acetate acid with ratio $25: 75$. The flow rate was $1 \mathrm{ml} / \mathrm{min}$ and run time set for $18 \mathrm{~min}$. UV detector wavelength was $320 \mathrm{~nm}$ and the injection volume was $20 \mu \mathrm{l}$. The sample was prepared in $80 \%$ ethanol as solvent. ${ }^{6}$ For comparison, the same sample without salt (only ethyl acetate fraction) was also analyzed.

Oxyresveratrol concentration $=\frac{\text { sample area }}{\text { standard area }} \times \frac{\text { standard volume injected }}{\text { sample volume injected }} \times C$ standard

\section{RESULTS}

\section{Determination the optimum IL Solution for IL-MAE}

Determination the optimum IL Solution for IL-MAE was analyzed by TLC-densitometry to compare three kinds IL solution with three concentrations. Oxyresveratrol concentration from each sample shown in Table 1. IL solution [Bmim] Br with concentration $1.5 \mathrm{~mol} / \mathrm{L}$ show 595.61 ppm as the highest oxyresveratrol content among the samples.

\section{Determination the optimum microwave power for IL-MAE}

Subsequently, extractionof IL solution $1.5 \mathrm{~mol} / \mathrm{L}$ [Bmim]Br with three different microwave power was analyzed by TLC-densitometry. Oxyresveratrol concentration from each sample shown in Table 2. Extraction using IL solution $1.5 \mathrm{~mol} / \mathrm{L}$ [Bmim] Br with microwave power $10 \%$ for $10 \mathrm{~min}$ showed the highest oxyresveratrol concentration among the samples was $463.02 \mathrm{ppm}$.

\section{Separation of oxyresveratrol from ionic liquid}

Four types of salts, $\mathrm{Na}_{2} \mathrm{CO}_{3}, \mathrm{NaHCO}_{3}, \mathrm{NaCl}$ and $\mathrm{K}_{2} \mathrm{HPO}_{4}$ solution with concentration $1.0 \mathrm{~mol} / \mathrm{L}, 0.1 \mathrm{~mol} / \mathrm{L}$, and $0.01 \mathrm{~mol} / \mathrm{L}$ respectively with ethyl acetate for back extraction, were studied to separated oxyresveratrol from the IL solution. The extract was obtained using IL concentration $1.5 \mathrm{~mol} / \mathrm{L}[\mathrm{Bmim}] \mathrm{Br}$ solution. These result can be shown in Figure 1. The $0.01 \mathrm{~mol} / \mathrm{L} \mathrm{NaHCO}_{3}$ had the best result to obtained oxyresveratrol among the other. Thus, the $0.01 \mathrm{~mol} / \mathrm{L} \mathrm{NaHCO}_{3}$ was chosen as the optimum salt.

\section{Determination of Oxyresveratrol by High-Performance Liquid Chromatography (HPLC) Analysis}

The sample in optimum condition $(1.5 \mathrm{~mol} / \mathrm{L}$ [Bmim] $\mathrm{Br}, 0.01 \mathrm{~mol} /$ $\mathrm{LNaHCO}_{3}$, microwave power $10 \%$ for $10 \mathrm{~min}$ ) was analyzed by HPLC. As comparison,oxyresveratrol standard and sample without $\mathrm{NaHCO}_{3}$ separation were also analyzed. The comparison of chromatogram and oxyresveratrol concentration between standard and samples were shown in Figure 2 and Table 3 respectively. Oxyresveratrol concentration on the sample with $0.01 \mathrm{~mol} / \mathrm{L} \mathrm{NaHCO}_{3}$ separation showed the highest result.

\section{DISCUSSION}

Oxyresveratrol is a substituted stilbene compound of hydroxyl groups found mostly in roots, stems, leaves and plant fruits of the Moraceae family, Liliaceae, and Gnetaceae..$^{7-8}$ Based on study above, [Bmim]Br was chosen as the optimum IL solution to obtain oxyresveratrol from M. Alba roots extract. IL solution could lower the surface tension of water and make it easier to penetrate the membrane to extract this compound. ${ }^{9}$ The determination of optimum ionic liquid is influenced by anions and 


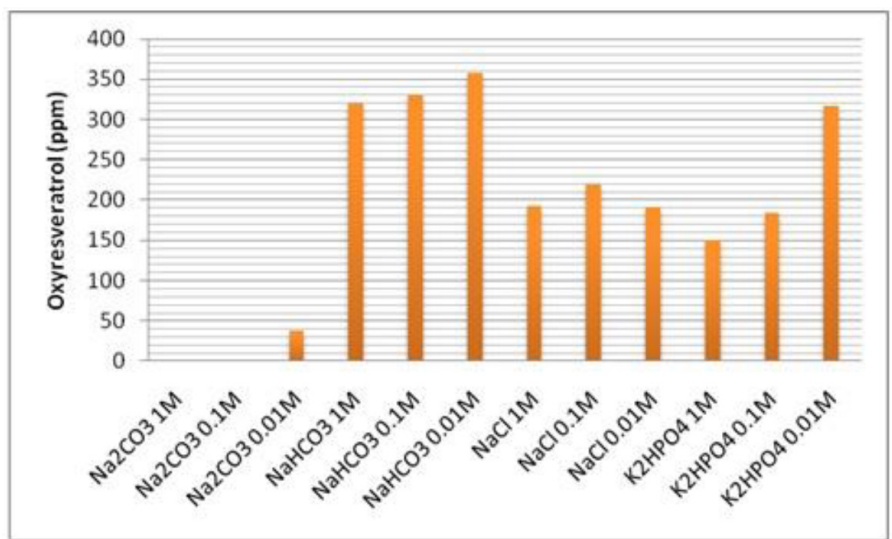

Figure 1: Comparison of oxyresveratrol concentration between sample using salts [source:original data].

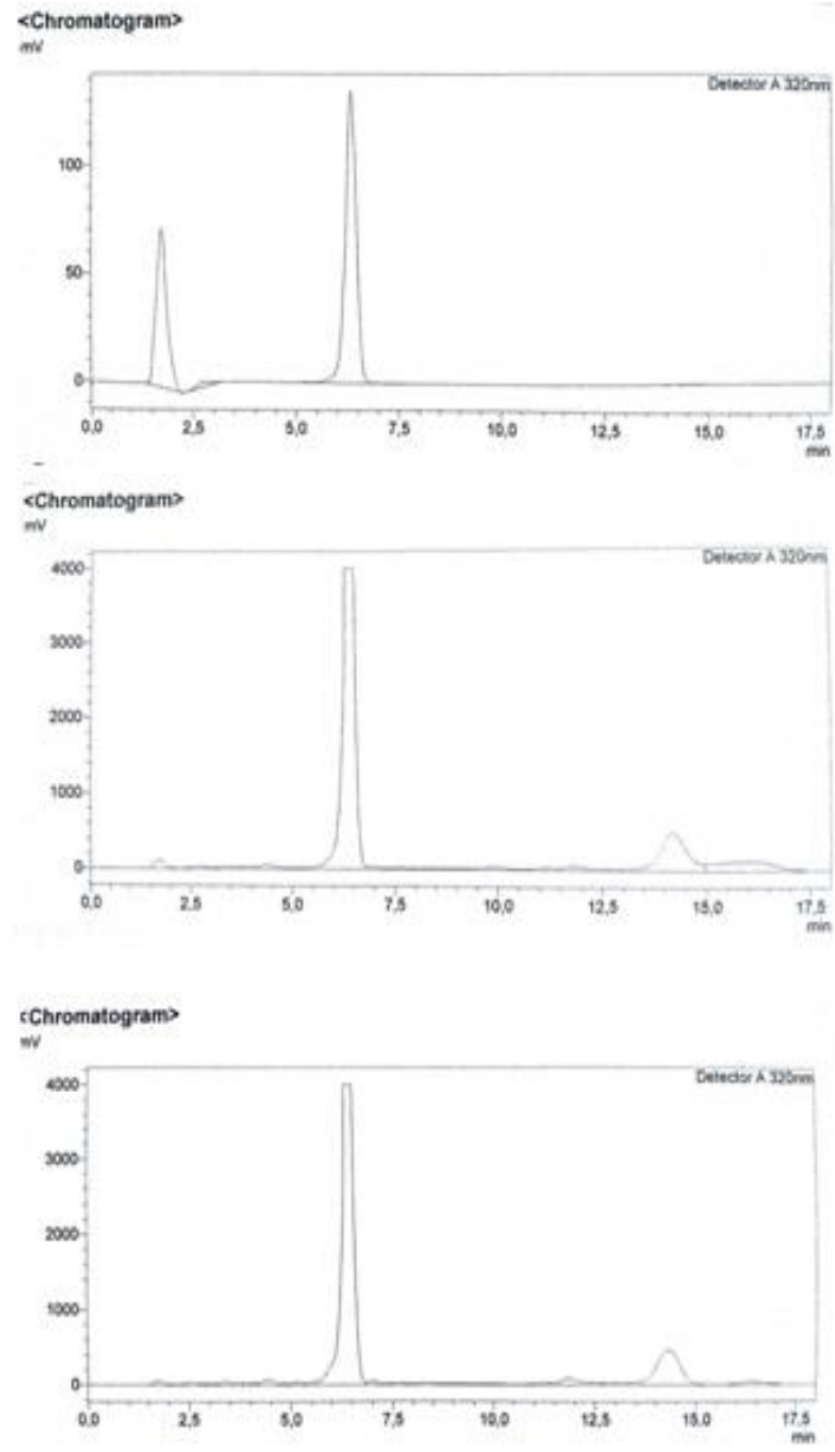

Figure 2: HPLC Chromatograms of standard oxyresveratrol 20 ppm (up), sample IL-MAE mulberry root extract with $0.01 \mathrm{~mol} / \mathrm{L} \mathrm{NaHCO}$ (middle) and sample IL-MAE mulberry root extract without salt (bottom) under detector $320 \mathrm{~nm}$ [source:original data].
Table 1: Oxyresveratrol concentration in Morus alba roots extract with different ionic liquid and concentration [source: original data]

\begin{tabular}{|c|c|c|c|c|c|c|}
\hline \multirow[t]{2}{*}{ No } & \multirow{2}{*}{$\begin{array}{l}\text { lonic } \\
\text { Liquids }\end{array}$} & \multirow{2}{*}{$\begin{array}{c}\text { Concentration } \\
(\mathrm{mol} / \mathrm{L})\end{array}$} & \multicolumn{3}{|c|}{$\begin{array}{c}\text { Oxyresveratrol } \\
\text { concentration (ppm) }\end{array}$} & \multirow{2}{*}{$\begin{array}{c}\text { Average } \\
\text { (ppm) }\end{array}$} \\
\hline & & & R1 & $\mathrm{R} 2$ & R3 & \\
\hline 1 & \multirow{3}{*}[\mathrm{Bmim}]{$\mathrm{Br}$} & 1.5 & 402.99 & 623.46 & 760.37 & 595.61 \\
\hline 2 & & 2 & 301.58 & 499.2 & 460.39 & 420.39 \\
\hline 3 & & 2.5 & 241.01 & 324.15 & 235.29 & 266.82 \\
\hline 4 & \multirow{3}{*}[\mathrm{Hmim}]{$\mathrm{Br}$} & 1.5 & 350.41 & 246.34 & 198.47 & 265.07 \\
\hline 5 & & 2 & 247.63 & 128.03 & 78.99 & 151.55 \\
\hline 6 & & 2.5 & 163.36 & 80.32 & 34.71 & 92.77 \\
\hline 7 & \multirow{3}{*}[\mathrm{Bmim}]{$_{2} \mathrm{SO}_{4}$} & 1.5 & 199.35 & 189.93 & 279.1 & 222.79 \\
\hline 8 & & 2 & 16.08 & 34.82 & 45.63 & 32.18 \\
\hline 9 & & 2.5 & 29.48 & 18.24 & nd & 15.91 \\
\hline
\end{tabular}

${ }^{*}$ nd : not detected; R1 : replication $1 ; \mathrm{R} 2$ : replication $2 ; \mathrm{R} 3$ : replication 3

Table 2: Optimization of microwave power for IL-MAE [source: original data]

\begin{tabular}{cccccc}
\hline & Nonic Liquid 1.5 & \multicolumn{3}{c}{ Oxyresveratrol concentration } & Average \\
\cline { 3 - 5 } & mol/L [Bmim] Br & R1 & R2 & R3 & (ppm) \\
\hline 1 & Power 10\% & 506.7 & 435.08 & 447.29 & 463.02 \\
2 & Power 30\% & 273.43 & 395.42 & 331.15 & 333,33 \\
3 & Power 50\% & 140.93 & 348.07 & 178.98 & 222.66 \\
\hline
\end{tabular}

Table 3: HPLC Analysis result of oxyresveratrol concentration [source:original data]

\begin{tabular}{cccc}
\hline & $\begin{array}{c}\text { Retention } \\
\text { time }\end{array}$ & Area & $\begin{array}{c}\text { Oxyresveratrol } \\
\text { concentration } \\
\text { (ppm) }\end{array}$ \\
\hline $\begin{array}{c}\text { Oxyresveratrol } \\
\text { standard 20 ppm }\end{array}$ & 6.376 & 2533153 & 20 \\
$\begin{array}{c}\text { Sample with 0.01 } \\
\text { mol/L NaHCO }\end{array}$ & 6.488 & 93124494 & 735.25 \\
Sample without salt & 6.504 & 87676311 & 692.23 \\
\hline
\end{tabular}

cations. The previous study declared that anion $\mathrm{Br}^{-}$is more efficient to attract trans-resveratrol than any other type of anion, $\mathrm{Br}>\mathrm{SO}_{4}$, because of the influence of acidity degree. Anion bromide ( $\mathrm{Br}$ ) make the ionic solution was slightly acid than another anion. The weak acid ionic solution could extract trans-resveratrol. ${ }^{10}$ Oxyresveratrol is a hydroxystilbene compound with four hydroxy groups, while trans-resveratrol with three hydroxy groups. ${ }^{2}$ Therefore oxyresveratrol as a derived compound of trans-resveratrol show the same result. Based on the type of cation, the efficiency of extraction increased by increasing the length of the alkyl chain from ethyl to butyl and starting decreases slowly from butyl to octyl, despite the hydrogen and hydrophobicity properties of hydrogen bonding increases. ${ }^{11-12}$ Finally, the ionic liquid [Bmim] Br (1-butyl3 methylimidazolium bromide) is chosen as the solvent because of the bonding effect. It was also probably due to the stronger bonds including $\Pi-\Pi$, ionic charges, and hydrogen interaction between IL and active compound. ${ }^{13}$

Based on the previous study, the optimum concentration of [Bmim] $\mathrm{Br}$ solution to get trans-resveratrol from Gnetum gnemon seeds was $2.5 \mathrm{~mol} / \mathrm{L}{ }^{8}$ 
The optimum IL concentration would make ionic liquid cleavage, penetrate into the cell membrane, and the bioactive compound would be dissolved. ${ }^{14}$ In this study, $[\mathrm{Bmim}] \mathrm{Br}$ solution with concentration $1.5 \mathrm{~mol} / \mathrm{L}$ was chosen as the optimum concentration of IL solution to obtain oxyresveratrol from $M$. alba roots extract. The ILs concentration associated with viscosity that affects the ability to penetrate and damage the plant cell walls. ${ }^{15}$ The lower concentration $(1.5 \mathrm{~mol} / \mathrm{L})$ than other obtain the better oxyresveratrol content from $M$. alba roots extract probably due to the effect of viscosity. The ionic liquid solvent is a thick liquid. The higher concentration is related to the viscosity of the solvent which increases. The higher viscosity of solution would affect less ability to obtain the target. ${ }^{16}$

The higher microwave power may be effective to extract compounds from plant materials using MAE in a short time. Otherwise, the higher microwave power for a long time can cause damage the active compound because of the overheat. Therefore, the higher microwave power obtains less oxyresveratrol from $M$. alba roots. Based on the previous study, the optimum power and extraction time to obtain trans-resveratrol from Gnetum gnemon seed was $10 \%$ and 10 min. ${ }^{8}$ This study showed the same result that optimum microwave power during IL-MAE in this study was $10 \%$ for $10 \mathrm{~min}$.

The optimum salt for this extraction method was $0.01 \mathrm{~mol} / \mathrm{L} \mathrm{NaHCO}_{3}$ which obtain the highest oxyresveratrol concentration among others. One of the methods to separate active compound from ionic liquid was phase separation with the salting-out process. The salt would help to precipitate residue in the IL solution, thus oxyresveratrol would migrate into an organic solvent easier than using no salt.

The optimum condition of IL-MAE of $M$. alba roots extract was ionic liquid $[\mathrm{Bmim}] \mathrm{Br}$ concentration $1.5 \mathrm{~mol} / \mathrm{L}$ with the $0.01 \mathrm{~mol} / \mathrm{L} \mathrm{NaHCO}_{3}$ salt solution with extraction value of oxyresveratrol concentration was $735.25 \mathrm{ppm}$ or $163.389 \mathrm{mg}$ oxyresveratrol/ g extract. If it is compared with maceration extraction, oxyresveratrol content from $M$. alba root with methanolic maceration extraction was $0.30 \mathrm{w} / \mathrm{w}$ by HPTLC and $0.27 \% \mathrm{w} / \mathrm{w}$ with HPLC. ${ }^{3}$

The use of microwave-assisted extraction is known to cause a cells tissue interference by a microwave irradiation will contribute to the extraction process. ${ }^{17} \mathrm{MAE}$ was proved to increase the extraction efficiency due to rapid heat process and lower temperatures prevent the compounds damage. ${ }^{18}$ MAE method was proven to be better in extraction efficiency, time, as well as quantity of solvent used..$^{19} \mathrm{MAE}$ is suitable for a compound which is easily degraded by heat such oxyresveratrol. The use of modern extraction methods has proven to be more efficient and economical for extracting the active components of the plant by using ionic liquid microwave-assisted extraction (IL-MAE). ${ }^{15}$

\section{CONCLUSION}

Ionic liquid-based microwave assisted extraction is a rapid and effective method for extraction of $M$. alba roots to obtain the optimum oxyresveratrol. The optimum condition of IL-MAE of M. alba roots extract was ionic liquid $[\mathrm{Bmim}] \mathrm{Br}$ concentration $1.5 \mathrm{~mol} / \mathrm{L}$ using microwave power $10 \%$ with the $0.01 \mathrm{~mol} / \mathrm{L} \mathrm{NaHCO}_{3}$ salt solution with extraction value of oxyresveratrol was $735.25 \mathrm{ppm}$, better than sample without using salt.

\section{ACKNOWLEDGEMENT}

This study was supported by Universitas Indonesia for Hibah PITTA 2017 Contract Number 13489.

\section{CONFLICT OF INTEREST}

The Authors have no conflict of interest to declare.

\section{ABBREVIATIONS}

IL: Ionic liquid; MAE: Microwave-assisted extraction; TLC: Thin layer chromatography; HPLC: High-performance liquid chromatography.

\section{REFERENCES}

1. Kang KB, Lee DY, Kim TB, Kim SH, Kim HJ, Kim J, et al. Prediction of Tyrosinase Inhibitory Activities of Morus alba Root Bark Extracts from HPLC fingerprints. Microchemical Journal. 2013;110:731-8.

2. Shin NH, Ryu SY, Choi EJ, Kang SH, Chang IM, Min KR, et al. Oxyresveratrol as the Potent Inhibitor of Dopa Oxidase Activity of Mushroom Tyrosinase. J Biochem Bioph Res Commun. 1998;243(3):801-3.

3. Ayinampudi SR, Wang Y, Avula B, Smillie TJ, Khan IA. Quantitative Analysis of Oxyresveratrol in Different Plant Parts of Morus Species and Related Genera by HPTLC and HPLC. 2011;24(2):125-9.

4. Du F, Xiao X, Li G. Application of ionic liquids in the microwave-assisted extraction of trans-resveratrol from Rhizoma Polygoni cuspidati. J Chroma. 2007; 1140(1-2):56-62.

5. Chemat F, Strube J. Green Extraction of Natural Products: Theory and Practice. Germany: Wiley-VCH Verlag Gmb H and Co. 2015.

6. Soonthornsit N, Pitaksutheepong C, Hemstapat W, Utaisincharoen P, Pitaksuteepong T. In vitro Anti-Inflammatory Activity of Morus Alba L. Stem Extract in LPS-Stimulated RAW 264.7 Cells. Evid-Based Comp and Alt Med. 2017. Article ID 3928956, 8 pages.

7. Xiong Y, Guo DA, Huang HL. Chemical constituents from tubers of Smilax china L. Modern Chinese Med. 2008;10:20-22

8. Ti HH, Wu P, Lin LD. Stilbenes and flavonoids from Artocarpus nitidus subsplingnanensis. Fitoterapia. 2011;82(4):662-5.

9. Ayuningtyas IN, Rahmawati M, Sutriyo, Mun'im A. Optimization of Ionic LiquidBased Microwave Assisted Extraction to Obtain Trans-resveratrol from Gnetum gnemon L. Seeds J Young Pharm. 2017;9(4):457-62.

10. Du F, Xiao X, Luo X, Li G. Application of ionic liquids in the microwaveassisted extraction of polyphenolic compounds from medicinal plants. Talanta. 2009;78(3):1177-84.

11. Wei Z, ZuY, Fu Y, Wang W,Zhao C, Pan Y. Ionic liquids-based microwave-assisted extraction of active components from pigeon pea leaves for quantitative analysis. Separation and Purification Technology. 2013;102:75-81.

12. Xu J, Wang W, Liang H, Zhang Q, Li Q. Optimization of ionic liquid-based ultrasonic-assisted extraction of antioxidant compounds from Curcuma longa L. using response surface methodology. Industrial Crops and Products. 2015;76:487-93.

13. Zhao C, Lu Z, Li C, He X, Li Z, Shi K, et al. Optimization of Ionic Liquid-Based Simultaneous Ultrasonic- and Microwave-Assisted Extraction of Rutin and Quercetin from Leaves of Velvet leaf (Abutilon theophrast) by Response Surface Methodology. The Scientific World Journal. 2014. Article ID 283024, 11 pages.

14. Rachmawati M, Ayuningtyas IN, Sutriyo S, Mun'im A. Comparison of Ionic Liquid-Microwave-Assisted Extraction and MAE of Resveratrol from Melinjo (Gnetum gnemon L.) Seeds. J App Pharm Sci. 2017;7(10):23-9.

15. Ahmad I, Yanuar A, Mulia K, Mun'im A. Application of Ionic Liquid based Microwave-Assisted Extraction of the Secondary Metabolite from Peperomiapellucida (L) Kunth. Pharmacognosy Journal. 2017;9(2):227-34.

16. Zhang J, Fan T, Xu J, Zhang S, Jiang M, Liu Q, et al. Application of ionic liquidbased microwave-assisted extraction of anthocyanin from Lycium ruthenicum. Sch J Eng Technol. 2016;4(2):113-7.

17. Ahmad I, Yanuar A, Mulia K, Mun'im A. Application of Ionic Liquid as a Green Solvent for Polyphenolics Content Extraction of Peperomia pellucida (L) Kunth Herb. J Young Pharm. 2017;9(4):486-90.

18. Liazid A, Palma M, Brigui J, Barroso CG. Investigation on phenolic compounds stability during microwave-assisted extraction. J Chromatogr A. 2007;1140(1-2): 29-34.

19. Bhan M, Satija S, Garg C, Dureja H, Garg M. A Novel Approach towards Green Extraction for Glycyrrhitinic Acid by Ionic Liquid Based Microwave Assisted Extraction and Optimization through Response Surface Methodology. Pharmacog J. 2017;9(6):866-72. 